\title{
Ebogotermes raphaeli, new genus and new species, an African soldierless termite described from the worker caste (Isoptera, Termitidae, Apicotermitinae)
}

\author{
RUDOLF H. SCHEFFRAHN ${ }^{1 *}$, YVES ROISIN ${ }^{2}$, PIERRE DIEUDONNÉ AKAMA ${ }^{3} \&$ JAN ŠOBOTNÍK ${ }^{4}$ \\ ${ }^{1}$ University of Florida, Fort Lauderdale Research \& Education Center, 3205 College Avenue Davie, Florida 33314 U.S.A. \\ ${ }^{2}$ Evolutionary Biology \& Ecology, Université Libre de Bruxelles (ULB), CP 160-12, Avenue F.D. Roosevelt 50 B-1050 Brussels, \\ Belgium. \\ झ"yves.roisin@ulb.be; 그ttps://orcid.org/0000-0001-6635-3552 \\ ${ }^{3} 4$ Département des sciences biologiques, Ecole normale supérieure, Université de Yaoundé I, BP 47 Yaoundé, Cameroon. \\ ":pieakama@hotmail.com; — https://orcid.org/0000-0003-0692-3837 \\ ${ }^{4}$ Faculty of Tropical AgriSciences, Czech University of Life Sciences, Prague, Kamýcká 129, 16500 Praha 6 - Suchdol, Czech \\ Republic. \\ झ"sobotnik@ftz.czu.cz; @ https://orcid.org/0000-0002-8581-637X \\ "Corresponding author. "rhsc@ufl.edu; @ https://orcid.org/0000-0002-6191-5963
}

\begin{abstract}
Ebogotermes raphaeli gen. n. sp. n., is described from workers collected in Cameroon. This soil-feeding termite is the largest soldierless termite from central Africa and aligns with the Anoplotermes subgroup. The enteric valve armature is weakly armed and, as with most apicotermitine species, is uniquely diagnostic.
\end{abstract}

Key words: Cameroon, enteric valve armature

\section{Introduction}

The "Treatise on the Isoptera of the World" (Krishna et al. 2013) established the benchmark for the taxonomic status of termites to the year 2011. At that time, 115 genera in four families and seven Termitidae subfamilies were recognized from the Ethiopian Region. Since then, the following seven Ethiopian genera have been added: Roisinitermes Scheffrahn, 2018 (Kalotermitidae); Isognathotermes Sjöstedt, 1926 n. comb. by Josens \& Deligne, 2021, Polyspathotermes Josens \& Deligne, 2021, and Ternicubitermes Josens \& Deligne, 2021 (Termitidae: Cubitermitinae, Hellemans et al. 2021); and Gastrotermes Scheffrahn, 2020, Apolemotermes Romero Arias \& Roisin, 2021, and Koutabatermes Romero Arias \& Roisin, 2021 (Termitidae: Apicotermitinae, Romero Arias et al. 2021). Furthermore, Romero Arias et al. 2021 have identified six additional monotypic apicotermitine genera from the Ethiopian Region using mitochondrial genome sequencing. Herein the worker denoted as 'Apicotermitinae genus L' (Romero Arias et al. 2021) is described as Ebogotermes raphaeli gen. n. sp. n..

\section{Material and methods}

All samples of Ebogotermes raphaeli were collected in primary forest near Ebogo II village. The preserved material was transported to Europe, subject to strict legal procedures, based on terms and conditions specified in Permits $\mathrm{N}^{\circ} 010 / \mathrm{MINRESI} / \mathrm{B} 00 / \mathrm{C00} / \mathrm{C} 10 / \mathrm{C} 12, \quad \mathrm{~N}^{\circ} 075 / \mathrm{MINRESI} / \mathrm{B} 00 / \mathrm{C} 00 / \mathrm{C} 10 / \mathrm{C} 12, \quad \mathrm{~N}^{\circ} 079 / \mathrm{CO} / \mathrm{MINFOF} / \mathrm{SETAT} / \mathrm{SG} /$ DFAP/SDVEF/SC/BJ, and $\mathrm{N}^{\circ} 079 / \mathrm{P} / \mathrm{MINFOF} / \mathrm{SETAT} / \mathrm{SG} / \mathrm{DFAP} / \mathrm{SDVEF} / \mathrm{SC} / \mathrm{BJ}$ (supervised by Dr. P. D. Akama). Preserved workers, stored in $85 \%$ ethanol, were positioned in a transparent petri dish filled with Purell ${ }^{\circledR}$ hand sanitizer $(70 \% \mathrm{EtOH})$. Body sections and dissected guts were photographed as multi-layer montages using a Leica M205C stereomicroscope with a Leica DFC 425 module run with Leica Application Suite software version 3. Mandibles and EVA within the proctodeal second segment (P2) were mounted on slides with PVA mounting medium 
(Bioquip Products, Inc.) and photographed with a Leica CTR 5500 compound microscope using bright field lighting and the same montage software. Terminology of the worker gut follows that of Sands (1998) and Noirot (2001). Measurements were obtained using an Olympus SZH stereomicroscope fitted with an ocular micrometer.

\section{Taxonomy}

\section{Ebogotermes Scheffrahn \& Roisin gen. nov.}

Type species. Ebogotermes raphaeli $\mathbf{s p .} \mathbf{n}$.

\section{Description}

Imago. Unknown.

Soldier. Unknown, belongs to a soldierless clade.

Diagnosis. Ebogotermes is the largest (Figs. 1,2) of the soldierless apicotermitine workers in equatorial Africa. The circular mesenteron, well-developed mixed segment, moderately long P1, P3/P4 isthmus, and long tubular P4 place Ebogotermes in the Anoplotermes-group (Noirot, 2001). Ebogotermes is closest to Aderitotermes Sands, 1972 workers (A. cavator and A. fossor) which Sands (1972) describes as being large (HW=0.90-0.99 mm) with the fore tibia "scarcely swollen" and a longer mixed segment than Ebogotermes. Unlike the pyriform enteric valve seating of Ebogotermes, Aderitotermes has trilobed seating. Also, the Ebogotermes EVA lacks fringes present in Aderitotermes.

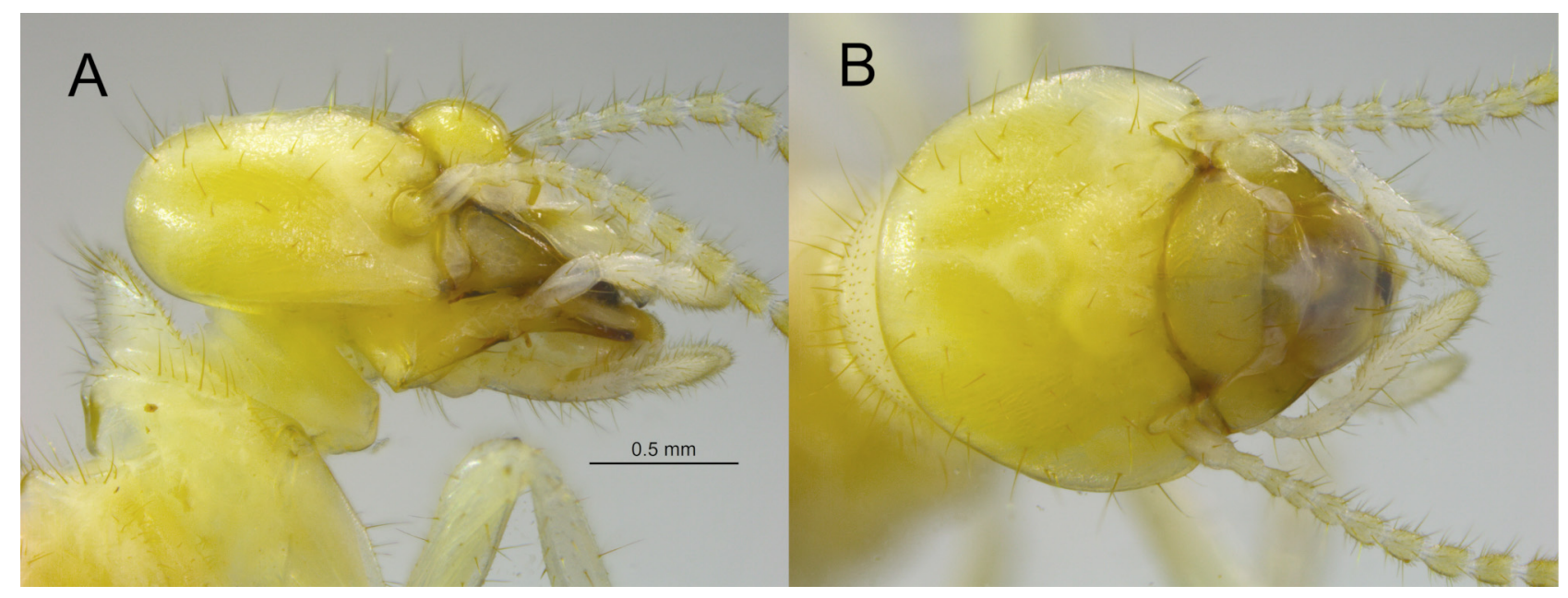

FIGURE 1. Ebogotermes raphaeli worker. A) Lateral and B) dorsal views of the head and pronotum.

Worker. Head, thorax, abdomen, and legs covered with setae of varying lengths. Antennae with 14 articles. Postclypeus moderately inflated. Fore tibia slightly inflated. Tibial spurs 3, 2, 2. Mesenteron forming circular loop; mixed segment about one fourth length of P1; P1 diameter greater than mesenteron, almost four times as long as wide. Enteric valve armature with six subequal ovoid cushions within lumen of P2. Paunch (P3) large, comprises about half the volume of entire gut.

Etymology. From Ebogo, a village near Mbalmayo in southern Cameroon, and Latin termes, termite. Gender: masculine

\section{Ebogotermes raphaeli Scheffrahn \& Roisin sp. n.}

Type Material. Holotype worker, Cameroon, Ebogo II, Jan Šobotník, University of Florida Termite Collection no. AFR3551 (Scheffrahn 2019), with 12 other workers (paratypes). Primary forest near Ebogo II village, 24FEB2019 
(CZU no. Cam19-1_PG_75). Paratype workers, J. Šobotník, primary forest near Ebogo II, (3.3820, 11.4632), elev. 677 m, UFTC no. AFR3617 (subsample of CAM20_PG_002). Paratype workers, Y. Roisin and J. Romero Arias, primary forest near Ebogo II, (3.3825, 11.4632), elev. 685 m, 7JUN2017 (ULB collection no. CMRT172), to be deposited in the Africa Museum (formerly Royal Museum of Central Africa, RMCA), Tervuren, Belgium.

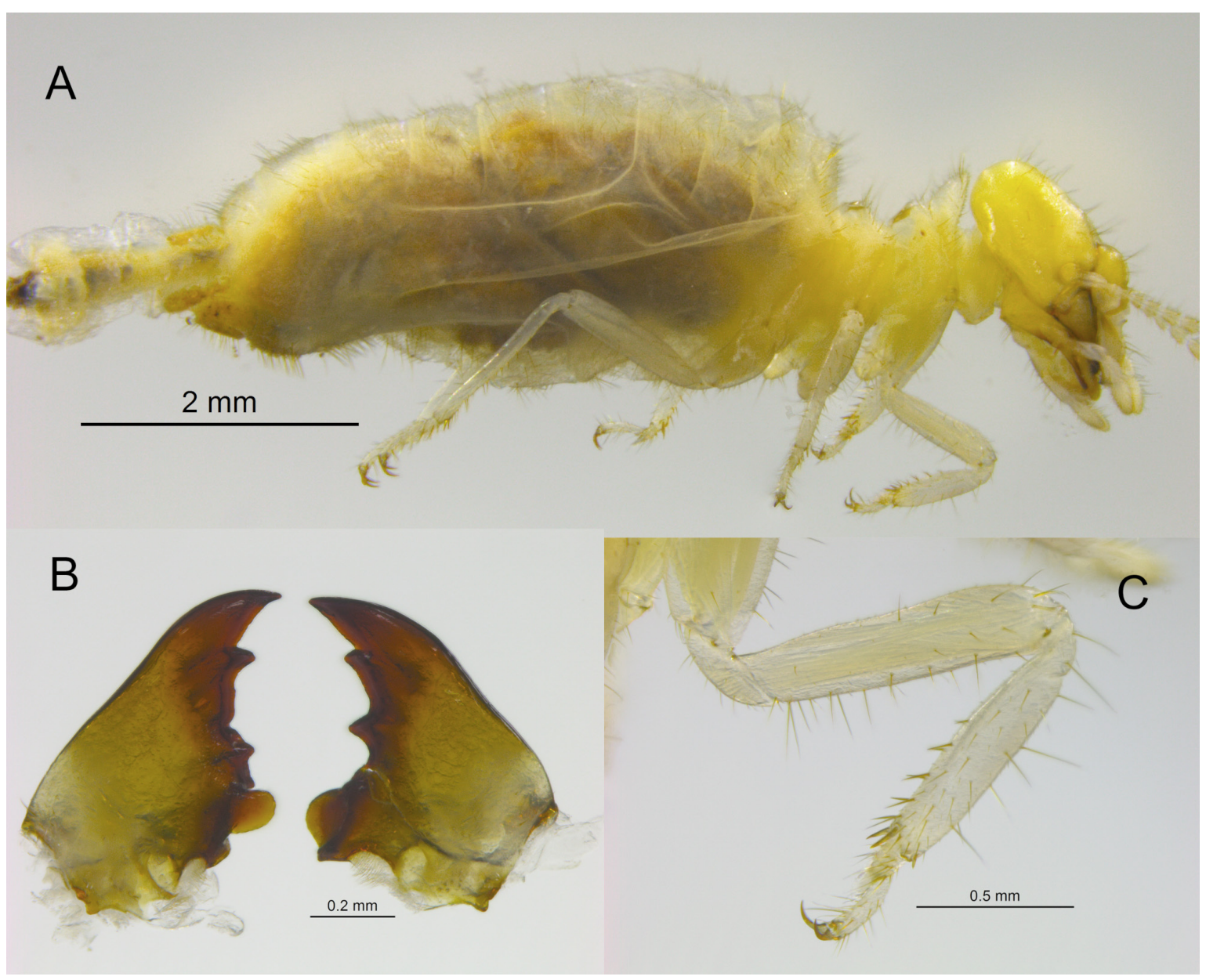

FIGURE 2. Ebogotermes raphaeli worker. A) Lateral habitus of whole worker, fifth proctodeal segment (rectum) prolapsed, B) mandibles, and C) right foreleg.
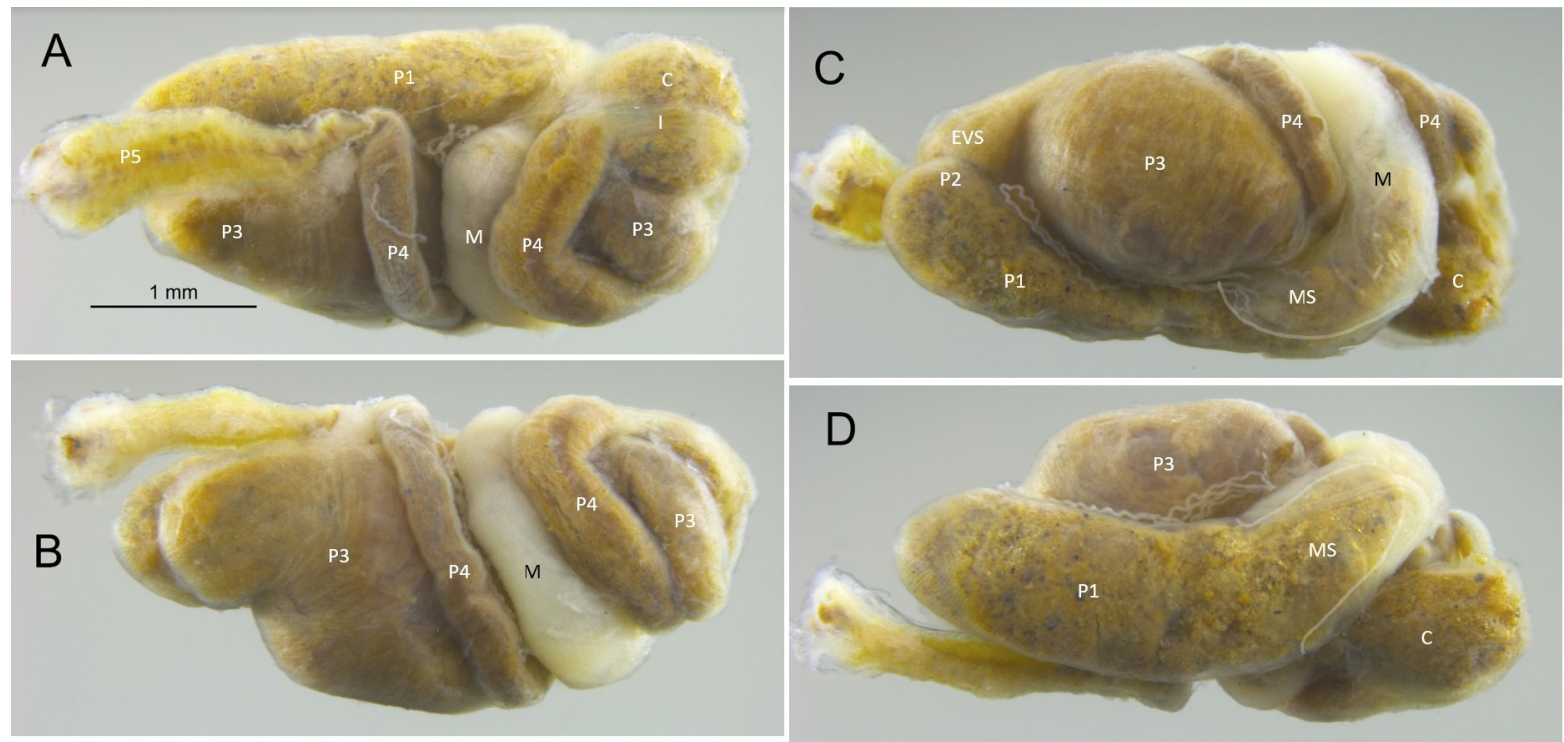

FIGURE 3. Ebogotermes raphaeli worker whole gut. A) dorsal, B) right, C) ventral, and D) left aspects. Abbreviations: C = crop, $\mathrm{M}=$ mesenteron, $\mathrm{MS}=$ mixed segment (margin highlighted in $\mathrm{C}$ and $\mathrm{D}$ ), $\mathrm{P} 1=$ first proctodeal segment, EVS = enteric valve seating, $\mathrm{P} 3$ = third proctodeal segment, $\mathrm{I}=$ isthmus, $\mathrm{P} 4$ = forth proctodeal segment, $\mathrm{P} 5$ = fifth proctodeal segment. 


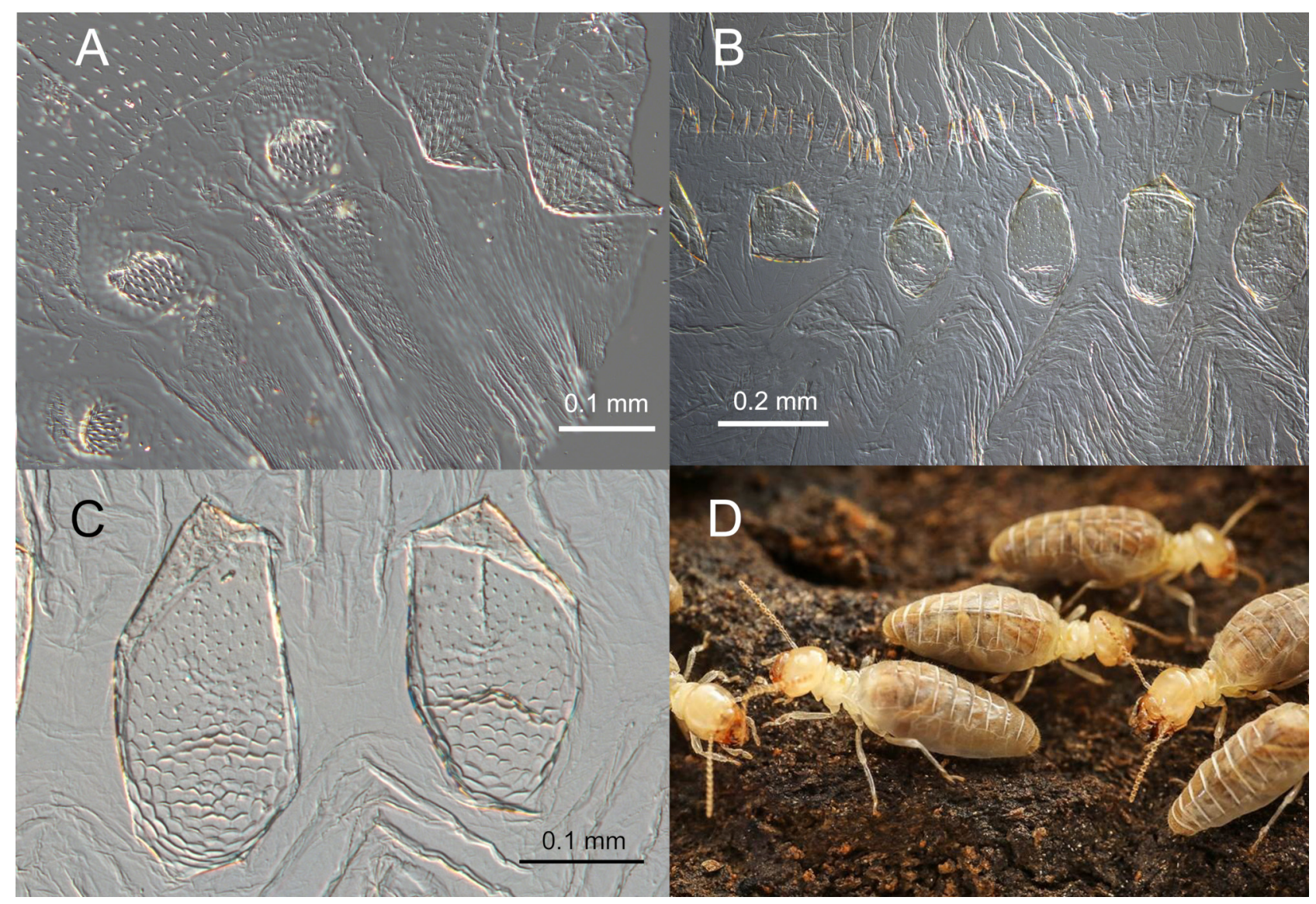

FIGURE 4. Ebogotermes raphaeli worker. A) Gizzard, showing the five spiny mats, B) enteric valve armature, C) detail of EVA cushions, and D) live habitus.

Type locality. Cameroon, Lekié, Ebogo, lat 3.3820, long 11.4632, elev. 677 m.

Diagnosis. The genus diagnosis will probably be consistent with any future new Ebogotermes species, however the EVA, the most diverse character in the Apicotermitinae, should reveal diagnostic differences.

Worker (Figs. 1-4). Very large. In lateral view (Fig. 1A), postclypeus moderately inflated; anterior lobe of pronotum tall, anterior rim covered with a field of small, uniform setae, posterior covered with about 35 setae of varying lengths. Posterior lobe of pronotum angled about $80^{\circ}$ from anterior lob. In dorsal view (Fig. 1B), head capsule covered with about 40 setae of varying lengths; fontanelle and large anterior frontal glands lighter than remainder of vertex. Mandibular dentition as in Fig. 2B. Fore tibia weakly inflated, about five time longer than wide. (Fig. 2C); about eight spines along inner margin, and three terminal spines; outer spine smallest. Antennal articles 1-4 about equal in length, article 5 and beyond wider and slightly longer. Mesenteric tongue of mixed segment lies along the inner side of the midgut ring (Fig. 3C). First proctodeal segment (P1) tubular, at least 2.5X long as wide (Fig. 3D). Second proctodeal segment (P2) armature does not extend into the lumen of the P3; EVA (Fig. 4B) consists of six cushions of similar shape that are either slightly larger or smaller than their neighbor. The anterior margin of each cushion is hemispherical while the posterior margin (pointing to the P3 lumen) is slightly sclerotized and forms a $90^{\circ}$ pouch. The surface of each cushion is adorned with ca. 70-140 scales rounded and broad near base of cushion, then narrowing into a tiny spine distally (Fig. 4C). Orientation of P2 to P3 $180^{\circ}$; P2 seating spheriform, without lobes. Third proctodeal segment (P3) expanding posteriorly from P2 seating lobe into voluminous main chamber (Fig. 3C) which bends to right and thins at P3/P4 isthmus at dorsal anterior. Fourth proctodeal segment (P4) long, narrow, and tubular, winding from isthmus around the anterior $\mathrm{P} 3$ for $180^{\circ}$, then bending posteriorly under $\mathrm{P} 3$, and finally bending $180^{\circ}$ around the middle of $\mathrm{P} 3$ from ventral side to terminate at P5 in dorsum. Measurements in Table 1.

Etymology. Named for Raphael Awoumou Onana, the chief of Ebogo village, a resilient guide, and expert on Cameroonian termites. 
TABLE 1. Measurements (mean, range in $\mathrm{mm}$ ) of Ebogotermes raphaeli workers ( $\mathrm{n}=10$ per colony).

\begin{tabular}{lrrr}
\hline & \multicolumn{3}{c}{ Colony } \\
\cline { 2 - 4 } Measurement & AFR3551 & CMRT172 & AFR3617 \\
\hline Head length to end of postclypeus & $0.95,0.89-1.00$ & $0.92,0.85-0.97$ & $0.93,0.88-0.98$ \\
Postclypeus length & $0.35,0.30-0.40$ & $0.30,0.28-0.31$ & $0.35,0.33-0.37$ \\
Maximum head width & $1.42,1.37-1.47$ & $1.35,1.32-1.38$ & $1.45,1.40-1.47$ \\
Pronotum width & $1.01,0.98-1.07$ & $0.93,0.91-0.96$ & $0.99,0.96-1.02$ \\
Hind tibia length & $1.44,1.37-1.49$ & $1.37,1.31-1.42$ & $1.45,1.37-1.53$ \\
Fore tibia length & $1.01,0.93-1.05$ & $1.04,1.00-1.06$ & $1.06,1.02-1.11$ \\
Fore tibia width & $0.19,0.18-0.19$ & $0.20,0.19-0.21$ & $0.19,0.18-0.21$ \\
Fore tibia width-to-length ratio & $0.19,0.18-0.20$ & $0.19,0.18-0.20$ & $0.18,0.16-0.20$ \\
\hline
\end{tabular}

\section{Discussion}

Ebogotermes is the largest of all Ethiopian apicotermitine workers along with the Namibian Skatitermes Coaton, 1971. Skatitermes has a wide range of worker head widths: Skatitermes psammophilus Coaton 1971 (1.18-1.20 $\mathrm{mm}$ ) and Skatitermes watti Coaton 1971 (1.18-1.56). Like many other rare apicotermitine genera (JŠ pers. obs.), Ebogotermes was always collected from humus-rich habitats between buttress roots of a large tree or under a fallen and partially decomposed white-rot log. There are quite a number of monotypic genera within Apicotermitinae (Krishna et al. 2013), showing a fast split and subsequent specialization of plentiful lineages during the Cenozoic in Africa and South America (Engel et al. 2009, Krishna et al. 2013, Bourguignon et al. 2017). Ebogotermes is a new member to this group, characterized by its large body size, unique unsclerotized enteric valve armature, and thin fore tibiae. Using complete mitochondrial genome sequencing, Romero Arias et al. 2021 place E. raphaeli (paratype colony CMRT172, identified as Apicotermitinae genus L) in the main clade of African soldierless Apicotermitinae. Ebogotermes raphaeli is most closely related to another new genus (labelled genus E) also with rather large-sized workers, whose study is in progress.

\section{Acknowledgments}

Many thanks to R. Onana, Ferdinand Onana, and Seraphin Bihina, our front-line termite collectors. We are also grateful to all other Ebogo villagers for their hospitality and help. Funding was provided by project FTZ IGA No. 20213112 to JŠ (Czech University of Life Sciences, Prague).

\section{References}

Bourguignon, T., Lo, N., Šobotník, J., Ho, S.Y.W., Iqbal, N., Coissac, E., Lee, M., Jendryka, M., Sillam-Dussès, D., Křížková, B., Roisin, Y. \& Evans, T.A. (2017) Mitochondrial phylogenomics resolves the global spread of higher termites, ecosystem engineers of the tropics. Molecular Biology and Evolution, 34, 589-597. https://doi.org/10.1093/molbev/msw253

Coaton, W.G.H. (1971) Five new termite genera from South West Africa (Isoptera: Termitidae). Cimbebasia, Series A, 2 (1), $1-34$.

Engel, M.S., Grimaldi, D.A. \& Krishna, K. (2009) Termites (Isoptera): Their phylogeny, classification, and rise to ecological dominance. American Museum Novitates, 3650, 1-27. https://doi.org/10.1206/651.1

Hellemans, S., Deligne, J., Roisin, Y. \& Josens, G. (2021) Phylogeny and revision of the 'Cubitermes complex' termites (Termitidae: Cubitermitinae). Systematic Entomology, 46: 224-238. https://doi.org/10.1111/syen.12458

Krishna, K., Grimaldi, D.A., Krishna, V. \& Engel, M.S. (2013) Treatise on the Isoptera of the World. Vols. 1-7. Bulletin of the American Museum of Natural History, 377, 1-2704. https://doi.org/10.1206/377.1 
Noirot, C. (2001) The gut of termites (Isoptera). Comparative anatomy, systematics, phylogeny. I. Higher termites (Termitidae). Annales de la Société Entomologique de France, Nouvelle Série, 37, 431-471.

Romero Arias, J., Chevalier, C. \& Roisin, Y. (2020) Anatomical specializations of the gizzard in soil-feeding termites (Termitidae, Apicotermitinae): Taxonomical and functional implications. Arthropod Structure \& Development, 57, 100942. https://doi.org/10.1016/j.asd.2020.100942

Romero Arias, J., Boom, A., Wang, M., Clitheroe, C., Šobotník, J., Stiblik, P., Bourguignon, T. \& Roisin, Y. (2021) Molecular phylogeny and historical biogeography of Apicotermitinae (Blattodea: Termitidae). Systematic Entomology, 46, $741-756$. https://doi.org/10.1111/syen.12486

Sands, W.A. (1972) The soldierless termites of Africa (Isoptera: Termitidae). Bulletin of the British Museum (Natural History), Entomology, Supplement 18, 1-244. https://doi.org/10.5962/p.192782

Sands, W.A. (1998) The identification of worker castes of termite genera from soils of Africa and the Middle East. CAB International, Wallingford, $500 \mathrm{pp}$.

Scheffrahn, R.H., Bourguignon, T., Akama, P.D., Sillam-Dussès, D. \& Šobotník, J. (2018) Roisinitermes ebogoensis gen. \& sp. n., an outstanding drywood termite with snapping soldiers from Cameroon (Isoptera, Kalotermitidae). ZooKeys, 787, 91-105. https://doi.org/10.3897/zookeys.787.28195

Scheffrahn, R.H. (2019) UF termite database. University of Florida termite collection. https://www.termitediversity.org/ (accessed 29 July 2021)

Scheffrahn, R.H. (2020) Gastrotermes spinatus gen. n. sp. n., an African soil-feeding termite described from the worker caste (Isoptera, Termitidae, Apicotermitidae). Zootaxa, 4789, 291-296.

https://doi.org/10.11646/zootaxa.4789.1.12 